\title{
Campur Kode Penggunaan Bahasa dalam Acara Ini Talkshow di Net Tv: Kajian Sosiolinguistik
}

\author{
Ni Luh Putu Rumpiani ${ }^{*}$, Ni Wayan Arnati

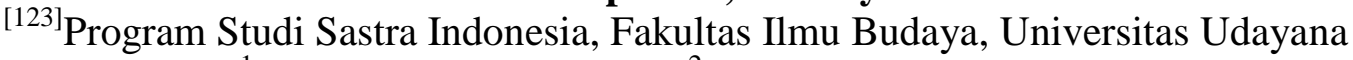 \\ [1viana994@yahoo.co.id], ${ }^{2}$ [wynarnati@gmail.com] \\ *Corresponding Author
}

\begin{abstract}
The study entitled "Mixed Language Usage Code In This Show Talkshow on Net Tv". There are three problems analyzed in this study, namely the types of code mix, mix language code language and the syntactic categories, and the factors that cause mixed code. The purpose of this study is to describe the types and mixed-code factors contained in the It Talkshow show on Net Tv. To achieve that goal used several methods and techniques. First, the process of collecting data using the method refer, which is assisted with techniques libat libat ably and technique record. Second, the process of data analysis used qualitative descriptive method and the method of agih, which is assisted by techniques of lesap. Third, the presentation of data analysis result is used informal method. The population in this study was 120 videos that aired from January to June 2016 downloaded from the youtube site. Sampling was done by quota sampling with 30 video samples. This research uses the theory developed by Fishman (1971), Jendra (2007), Chaer and Agustin (2010), and Chaer (2014). Based on the analysis that has been done in this show Talkshow on Net Tv, obtained results (1) types of mixed codes found, ie mixed into the code comes from Sundanese, Java, Batak, Betawi, and Bali. The mixed code comes from English and Arabic, and mixed mixed code comes from Sundanese and English; (2) mixed code based on the linguistic level found in the form of clause level, the phrase level is divided into the endocentric phrase and the exocentric phrase, the word level is divided into two, ie the word and the word back, and the syntactic categories found in the form of noun category, verb category, category adjectives, and pronoun categories; and (3) the factors behind the code mix are influenced by participants' speech factor, language factor, and factor of purpose of conversation.
\end{abstract}

Keywords: mixed code, sociolinguistics, and talkshow

\begin{abstract}
Abstrak
Penelitian ini berjudul "Campur Kode Penggunaan Bahasa dalam Acara Ini Talkshow di Net Tv". Ada tiga masalah yang dianalisis dalam penelitian ini, yaitu jenis-jenis campur kode, campur kode tataran kebahasaan serta kategori sintaksis, dan faktor-faktor penyebab campur kode. Tujuan penelitian ini adalah menggambarkan jenis-jenis dan faktor-faktor campur kode yang terdapat dalam acara Ini Talkshow di Net Tv. Untuk mencapai tujuan tersebut digunakan beberapa metode dan teknik. Pertama, proses pengumpulan data menggunakan metode simak, yang dibantu dengan teknik simak libat
\end{abstract}


cakap dan teknik catat. Kedua, dalam proses analisis data digunakan metode deskriptif kualitatif dan metode agih, yang dibantu dengan teknik lesap. Ketiga, dalam penyajian hasil analisis data digunakan metode informal. Populasi dalam penelitian ini adalah 120 video yang ditayangkan dari Januari sampai dengan Juni 2016 diunduh dari situs youtube. Pengambilan sampel dilakukan secara quota sampling dengan 30 sampel video. Penelitian ini menggunakan teori yang dikembangkan oleh Fishman (1971), Jendra (2007), Chaer dan Agustin (2010), dan Chaer (2014). Berdasarkan analisis yang telah dilakukan pada acara Ini Talkshow di Net Tv, didapatkan hasil (1) jenis-jenis campur kode yang ditemukan, yaitu campur kode ke dalam berasal dari bahasa Sunda, Jawa, Batak, Betawi, dan Bali. Campur kode ke luar berasal dari bahasa Inggris dan Arab, dan campur kode campuran berasal dari bahasa Sunda dan Inggris; (2) campur kode berdasarkan tataran kebahasaan yang ditemukan berupa tataran klausa, tataran frasa dibagi atas frasa endosentrik dan frasa eksosentrik, tataran kata dibagi menjadi dua, yaitu kata dasar dan kata ulang, serta kategori sintaksis yang ditemukan berupa kategori nomina, kategori verba, kategori adjektiva, dan kategori pronomina; dan (3) faktor penyebab campur kode dipengaruhi oleh faktor peserta bicara, faktor bahasa, dan faktor tujuan pembicaraan.

Kata kunci: campur kode, sosiolinguistik, talkshow

\section{Latar Belakang}

Bahasa mempunyai fungsi dan kedudukan yang sangat penting dalam kehidupan manusia, terutama fungsi komunikasi. Komunikasi adalah suatu proses, yakni informasi antarindividual ditukarkan melalui sistem simbol, tanda, atau tingkah laku yang umum (Chaer, 2014:44). Salah satu aplikasi bahasa sebagai alat komunikasi dalam bidang kesenian adalah penggunaan bahasa dalam media audiovisual, seperti kesenian dalam gelar wicara Ini Talkshow di Net Tv. Dewasa ini, di televisi semakin marak ditayangkan acara dengan menggunakan unsur bahasa lain dalam suatu bahasa yang mengandung campur kode. Unsur-unsur bahasa lain dalam suatu bahasa yang digunakan dalam acara Ini Talkshow menarik untuk diteliti. Acara ini belum pernah diteliti dan dikaji. Ini Talkshow mulai ditayangkan 29 Maret 2014 sehingga merupakan salah satu acara baru. Hal yang menarik dalam acara Ini Talkshow adalah pemakaian bahasa dengan campur kode yang digunakan dalam acara tersebut. Dalam acara ini ditemukan adanya unsur bahasa lain masuk dalam penggunaan bahasa Indonesia.

\section{Rumusan Masalah}

Berdasarkan latar belakang di atas, dapat dirumuskan tiga pokok permasalahan dalam penelitian ini. Ketiga permasalahan tersebut diuraikan sebagai berikut.

a. Jenis-jenis campur kode apa sajakah yang terdapat dalam penggunaan bahasa pada acara Ini Talkshow di Net Tv dilihat berdasarkan unsur bahasa yang disusupkan?

b.Campur kode pada tataran kebahasaan dan kategori sintaksis apa sajakah yang terdapat dalam penggunaan bahasa pada acara Ini Talkshow di Net Tv?

c.Faktor-faktor apa sajakah yang menyebabkan terjadinya campur kode dalam penggunaan bahasa pada acara Ini Talkshow di Net Tv?

\section{Tujuan Penelitian}

Secara umum penelitian ini bertujuan untuk menggambarkan campur kode dan 
memperoleh informasi mengenai faktorfaktor penyebab terjadinya campur kode dalam acara Ini Talkshow di Net Tv. Secara khusus penelitian ini memiliki tiga tujuan sebagai berikut.

a. Untuk mengetahui jenis-jenis campur kode yang terdapat dalam penggunaan bahasa pada acara Ini Talkshow di Net Tv dilihat berdasarkan unsur bahasa yang disusupkan.

b. Untuk mengetahui campur kode pada tataran kebahasaan dan kategori sintaksis yang terdapat dalam penggunaan bahasa pada acara Ini Talkshow di Net tv.

c. Untuk mengetahui faktor-faktor yang menyebabkan terjadinya campur kode dalam penggunaan bahasa pada acara Ini Talkshow di Net Tv.

\section{Metode Penelitian}

Metode dan teknik pengumpulan data yang digunakan dalam penelitian ini adalah metode simak dengan teknik simak bebas libat cakap dan teknik catat. Pada tahap analisis data digunakan metode deskriptif kualitatif dan metode agih dengan teknik lesap. Hasil analisis data disajikan dengan metode informal.

\section{Hasil dan Pembahasan}

Pembahasan pada penelitian ini dilakukan berdasarkan data yang telah terkumpul. Analisis penelitian ini dibagi menjadi beberapa uraian sebagai berikut.

\subsection{Jenis-Jenis Campur Kode dalam Penggunaan Bahasa pada Acara Ini Talkshow di Net Tv Berdasarkan Unsur Bahasa yang Disusupkan}

Jendra (2007:168) membagi campur kode menjadi tiga jenis, yaitu campur kode ke dalam, campur kode ke luar, dan campur kode campuran. Untuk lebih jelasnya ketiga campur kode tersebut diuraikan sebagai berikut.

\subsubsection{Campur Kode ke Dalam}

Campur kode ke dalam adalah campur kode yang menyusupkan unsurunsur bahasa asli yang masih sekerabat (Jendra, 2007:168). Campur kode yang ditemukan pada acara Ini Talkshow di Net Tv dapat diuraikan sebagai berikut.

(a) Penyusupan unsur bahasa Sunda

(2) Giring Nidji ada hiji di sana luar biasa arti sahabat. (hlm. 26)

(b)Penyusupan unsur bahasa Jawa

(4) Ini deweke kan ceritanya mau nengokkin temennya ... (hlm. 29)

(c) Penyusupan unsur dialek Betawi

(5) Kita berjumpa lagi di Ini talkshow eh gua mau nyapa Mang Saswi. (hlm. 31)

(d) Penyusupan unsur bahasa Batak

(6) Itu sama abang Arjoni.

(hlm. 32)

(e)Penyusupan unsur bahasa Bali

(7) Suksma ada yang mau tatto. (hlm. 33)

Dari data di atas diketahui terdapat contoh peristiwa campur kode berupa kata dengan unsur bahasa daerah ke dalam pemakaian bahasa Indonesia. Kata-kata yang merupakan penyusupan bahasa daerah, yaitu kata hiji 'satu', deweke 'dia', gua 'saya', abang 'kakak', dan suksma 'terima kasih'.

\subsubsection{Campur Kode ke Luar}

Campur kode ke luar adalah campur kode penyusupan unsur-unsur bahasa asing ke dalam pemakaian bahasa Indonesia (Jendra, 2007:168). Campur kode yang ditemukan pada acara Ini Talkshow di Net $\mathrm{Tv}$ dapat diuraikan sebagai berikut.

(a)Penyusupan unsur bahasa Inggris

(8) Iya betul security saya kasi tau dance. 
(hlm. 34)

(b)Penyusupan unsur bahasa Arab (10) Ana sing ngarep pingin ketemu kowe nang umahe Sule

(hlm. 38)

Dari data di atas diketahui terdapat contoh peristiwa campur kode berupa kata dengan unsur bahasa asing ke dalam pemakaian bahasa Indonesia. Kata-kata yang merupakan penyusupan bahasa asing, yaitu kata security 'keamanan', dance 'menari', dan ana 'saya'.

\subsubsection{Campur Kode Campuran}

Campur kode campuran adalah pemakaian bahasa Indonesia disertai unsur bahasa daerah dan bahasa asing (Jendra, 2007:168). Campur kode campuran yang ditemukan pada acara Ini Talkshow di Net $\mathrm{Tv}$ dapat diuraikan sebagai berikut.

(11)Bravo-bravo neng Cinta bisa semuanya. Untuk suara ni neng Cinta kan bagus sekali kira-kira minum apa sih?

(hlm. 39)

Dari data di atas diketahui terdapat contoh peristiwa campur kode berupa kata dengan unsur bahasa asing dan bahasa daerah ke dalam pemakaian bahasa Indonesia. Kata yang merupakan penyusupan bahasa asing, yaitu bravobravo 'bagus-bagus' dan penyusupan bahasa daerah, yaitu neng 'panggilan untuk perempuan yang lebih muda'.

\subsection{Campur Kode Berdasarkan Tataran Kebahasaan dan Kategori Sintaksis dalam Penggunaan Bahasa pada Acara Ini Talkshow di Net Tv}

Campur kode tataran kebahasaan dapat dibagi menjadi tiga, yaitu campur kode tataran klausa campur kode tataran frasa ditemukan frasa endosentrik dan frasa eksosentrik, dan campur kode tataran kata. Menurut Alwi dkk. (2003:36), kategori sintaksis dapat dibagi menjadi kategori nomina, kategori verba, kategori adjektiva, dan kategori pronomina. Untuk lebih jelasnya diuraikan sebagai berikut

\subsubsection{Campur Kode Tataran Klausa}

Klausa adalah satuan gramatikal yang berupa gabungan kata yang sekurang-kurangnya terdiri atas subjek dan predikat (Kridalaksana, 2008:124). Campur kode tataran klausa yang ditemukan pada acara Ini Talkshow di Net Tv, yaitu penyusupan unsur bahasa asing (Inggris) ke dalam pemakaian bahasa Indonesia dapat diuraikan sebagai berikut.

(13) I love you Andre ada yang mau ditanya lagi.

(hlm. 43)

Dari data di atas diketahui terdapat contoh peristiwa campur kode ditemukan klausa yang terdiri atas subjek $i$ 'aku/saya', predikat love 'cinta', dan objek you 'kamu'.

\subsubsection{Campur Kode Tataran Frasa}

Frasa adalah satuan gramatikal yang berupa gabungan kata yang bersifat non predikatif atau lazim juga disebut gabungan kata yang mengisi salah satu fungsi sintaksis di dalam kalimat (Chaer, 2014:222). Frasa dapat dibagi menjadi dua, yaitu frasa endosentrik dan eksosentrik. Contoh frasa penyusupan dengan unsur bahasa asing ke dalam pemakaian bahasa Indonesia yang ditemukan pada acara Ini talkshow di Net Tv dapat diuraikan sebagai berikut.

(a) Frasa Endosentrik

(17) Itu small phone begitu.

(hlm. 46) 
(b) Frasa Eksosentrik

(22) Oke sudah ada Vega di sini nanti kita akan ngobrol-ngobrol lagi di diye wae. (hlm. 50)

Dari data di atas diketahui terdapat contoh peristiwa campur kode yang ditemukan frasa endosentrik atributif, yaitu komponen pertama small 'kecil' dapat dilesapkan karena sebagai penjelas, sedangkan komponen kedua phone 'telepon', dapat menggantikan kedudukan frasa. Frasa di diye wae termasuk frasa eksosentrik apabila kata wae dihilangkan. Hal itu disebabkan oleh frasa di diye 'di sini' yang tidak dapat digantikan dengan $d i$ saja. Dengan demikian, terdapat frasa di diye dalam frasa di diye wae.

\subsubsection{Campur Kode Tataran Kata}

Klasifikasi kata yang ditemukan pada acara Ini talkshow di Net Tv, yaitu kata dasar adalah satuan bahasa terkecil yang memiliki makna dan kata ulang adalah proses morfologis yang mengulang bentuk dasar, baik secara keseluruhan, secara sebagian, maupun dengan perubahan bunyi (Chaer dan Agustina, 2010:182). Contoh kata dasar dan kata ulang dapat diuraikan sebagai berikut.

\section{(a) Kata Dasar}

(23) Colour tetapi dengar-dengar katanya mau lanjut kuliah di Harvad university. (hlm. 51)

\section{(b) Kata Ulang}

(11) Bravo-bravo neng Cinta bisa semuanya.

Dari data di atas diketahui terdapat contoh peristiwa campur kode dengan unsur bahasa Inggris, yaitu colour 'warna', university 'universitas', dan bravo-bravo 'bagus-bagus ke dalam pemakaian bahasa Indonesia.

\subsubsection{Kategori Sintaksis}

Kategori sintaksis dapat dibagi menjadi kategori nomina, kategori verba, kategori adjektiva, dan kategori pronomina (Alwi dkk, 2003:36). Berikut contoh kategori sintaksis yang ditemukan pada acara Ini Talkshow di Net Tv.

(a) Kategori Nomina

(25) Kirain aku warna cokelat kalau chocolate sendiri ya aku suka cokelat. (hlm.55)

(b) Kategori Verba

(27) Ya lagi nyiapin lagu, sebenarnya sih sudah recording. (hlm. 57)

(c) Kategori Adjektiva

(28) Saya ini yang terobsesi ingin menjadi artis luar negri si Jeni love. (hlm. 57)

(d) Kategori Pronomina

(29) Bapak gua mana pernah romantis, bapak gua sama emak gua diem gak ada romantisna. (hlm.59)

Dari data di atas diketahui terdapt peristiwa campur kode dengan penyusupan unsur bahasa Inggris, yaitu kata chocolate 'cokelat' dalam kategori nomina, recording 'rekaman' dalam kategori verba, dan love 'cinta' dalam kategori adjektiva. Penyusupan unsur dialek Betawi, yaitu gua 'saya' merupakan kata ganti orang pertama.

\subsection{Faktor-faktor Penyebab Campur Kode dalam Penggunaan Bahasa pada Acara Ini Talkshow di Net Tv}

Faktor-faktor yang melatarbelakangi campur kode pada acara Ini Talkshow dibagi menjadi faktor peserta bicara, faktor bahasa, dan faktor tujuan pembicaraan (Jendra, 2007:171). Untuk lebih jelasnya diuraikan sebagai berikut. 


\subsubsection{Faktor Peserta Bicara}

Peserta bicara adalah orang yang terlibat dalam suatu percakapan atau pembicaraan. Setiap peserta bicara memiliki kemampuan berbahasa yang berbeda. Pembawa acara pada acara Ini Talkshow di Net Tv mampu menguasai lebih dari satu bahasa dan dalam penggunaan bahasa. Mereka sering mencampurkan unsur bahasa lain untuk menciptakan tuturan yang bervariasi dan menimbulkan kesan lucu serta menarik walaupun bahasa yang digunakan terkadang tidak sesuai dengan kaidahkaidah kebahasaan pada umumnya. Contoh data dapat diuraikan sebagai berikut.

(8) Wait jangan salah kakek aku dulu jenderal angkatan udara. (hlm.61)

Dari data di atas diketahui terdapat tuturan peristiwa campur kode dengan unsur bahasa Inggris dalam bentuk kata. Peserta bicara berpengaruh pada bahasa yang digunakan, dilihat dari latar belakang Cinta seorang artis yang berasal dari Jerman kerap menyusupkan unsur bahasa asing ke dalam pemakaian bahasa Indonesia.

\subsubsection{Faktor Bahasa}

Bahasa adalah kemampuan yang dimiliki untuk berkomunikasi dengan sesama manusia lainnya. Dalam sebuah acara gelar wicara, baik bintang tamu maupun pembawa acara, melakukan campur kode, baik dengan unsur bahasa asing maupun bahasa daerah ke dalam pemakaian bahasa Indonesia. Unsur bahasa asing digunakan agar lebih bergengsi dalam tuturan/kalimat, sedangkan unsur bahasa daerah digunakan sebagai identitas suatu daerah dan sebagai sarana pencipta keakraban antara penutur dan lawan tutur. Contoh data dapat diuraikan sebagai berikut.
(14) Senang show katanya Andre silahkan mau ngobrol lagi Ndre. (hlm. 63)

Dari data di atas diketahui terdapat peristiwa tuturan dengan unsur bahasa Inggris dalam bentuk kata. Pada tuturan tersebut kata dari bahasa asing yang digunakan menurut penutur memberikan kesan bergengsi.

\subsubsection{Faktor Tujuan Pembicaraan}

Setiap komunikasi memiliki tujuan yang hendak dicapai untuk menyampaikan suatu informasi. Seseorang terkadang menggunakan unsur-unsur bahasa yang berasal dari luar bahasa tersebut dalam memberikan informasi. Terjadinya peristiwa campur kode dalam suatu komunikasi bertujuan agar informasi yang disampaikan menjadi lebih jelas sehingga tujuan dapat sampai lebih cepat dan tepat. Contoh data dapat diuraikan sebagai berikut.

(25) Kirain aku warna cokelat kalau chocolate sendiri ya aku suka cokelat. (hlm. 64)

Dari data di atas diketahui terdapat tuturan peristiwa campur kode dengan unsur bahasa Inggris dalam bentuk kata. Kata chocolate 'cokelat' adanya usaha untuk memberikan penjelasan dari salah satu unsur bahasa. Adapun tujuannya agar dapat dipahami pengertiannya sesuai dengan yang diharapkan sehingga komunikasi dapat tercapai dengan tepat dan cepat.

\section{Simpulan}

Dalam acara Ini Talkshow di Net TV ditemukam jenis campur kode, campur kode tataran kebahasaan, kategori sintaksis, dan faktor-faktor penyebab campur kode. Berdasarkan jenis campur kode ditemukan campur kode ke dalam penyusupan dengan unsur bahasa daerah 
(Sunda, Jawa, Batak, Betawi, dan Bali), campur kode ke luar penyusupan dengan unsur bahasa asing (Inggris dan Arab), dan campur kode campuran peyusupan dengan unsur bahasa daerah (Sunda, Betawi, dan Jawa) serta bahasa asing (Inggris dan Arab) ke dalam pemakaian bahasa Indonesia. Berdasarkan campur kode tataran kebahasaam ditemukan campur kode tataran klausa penyusupan dengan unsur bahasa asing (Inggris), campur kode tataran frasa dibagi menjadi dua, yaitu pertama frasa endosentrik atributif yang ditemukan adalah penyusupan dengan unsur bahasa asing (Inggris) dan daerah (Jawa dan Sunda), dan kedua frasa eksosentrik yang ditemukan adalah penyusupan dengan unsur bahasa daerah (Sunda) ke dalam pemakaian bahasa Indonesia. Berdasarkan kategori sintaksis campur kode yang ditemukan terdiri atas kategori nomina penyusupan dengan unsur bahasa asing (Inggris) dan bahasa daerah (Sunda), kategori verba penyusupan dengan unsur bahasa asing (Inggris), kategori adjektiva penyusupan dengan unsur bahasa asing (Inggris) dan bahasa daerah (Jawa), dan kategori pronomina penyusupan dengan unsur bahasa daerah (Betawi) ke dalam pemakaian bahasa Indonesia. Berdasarkan faktor-faktor penyebabnya dapat dibagi atas faktor peserta bicara berpengaruh pada bahasa yang digunaka, faktor bahasa yakni seseorang kurang loyal dengan bahasanya sendiri sehingga saat berinteraksi sering menyusupkan unsur bahasa lain, dan faktor tujuan pembicaraan adalah adanya usaha untuk memberikan penjelasan dari salah satu unsur bahasa.

\section{Daftar Pustaka}

Alwi, Hasan dkk. 2003. Tata Bahasa Baku Bahasa Indonesia. Edisi Ketiga. Jakarta: Balai Pustaka.

Chaer, Abdul dan Leoni, Agustina. 2010. Sosiolinguistik Perkenalan Awal Edisi Revisi. Jakarta: PT Rineka Cipta.

Chaer, Abdul. 2014. Linguistik Umum. Jakarta: Rineka Cipta.

Jendra, I Wayan. 2007. Sosiolinguistik, Teori dan Penerapannya. Surabaya: Paramita.

Kridalaksana, Harimurti. 2008. Kamus Linguistik. Jakarta: PT Gramedia Pustaka Utama. 